\title{
25 Research Square \\ Distinct Dyadic Quality of Life Profiles Among Advanced Lung Cancer Patient-Caregiver Dyads: A Latent Profile Analysis
}

\author{
Hui Wang \\ Shandong University Cheeloo College of Medicine \\ Tiantian Deng \\ Shandong University Cheeloo College of Medicine \\ Cong Cao \\ Shandong University Cheeloo College of Medicine \\ Danjun Feng ( $\nabla$ fdj19@sdu.edu.cn ) \\ Shandong University Cheeloo College of Medicine https://orcid.org/0000-0003-0310-3657
}

\section{Research Article}

Keywords: Latent profile analysis, Dyadic quality of life, Neuroticism, Resilience, Family functioning

Posted Date: January 25th, 2022

DOI: https://doi.org/10.21203/rs.3.rs-1199351/v1

License: (1) This work is licensed under a Creative Commons Attribution 4.0 International License. Read Full License 


\section{Abstract \\ Purpose}

This study aimed to identify the heterogeneity of dyadic quality of life ( $Q \circ L)$ profiles, determine whether these profiles differ in terms of demographic and medical factors, neuroticism, resilience, and family functioning, and explore the combined effect of patient and caregiver neuroticism, resilience, and family functioning on dyadic QoL profiles.

\section{Methods}

A cross-sectional study was conducted with 304 advanced lung cancer patient-caregiver dyads enrolled from radiotherapy and chemotherapy departments at three tertiary hospitals. Self-report questionnaires were administered to patient-caregiver dyads to assess demographic and medical characteristics, neuroticism, resilience, family functioning and QoL.

\section{Results}

The latent profile analysis identified four subgroups of dyadic QoL: patient low-caregiver high profile (38.82\%), patient high-caregiver high profile (22.37\%), patient high-caregiver low profile (19.74\%), and patient low-caregiver low profile (19.08\%). Additionally, when both patients and their caregivers had a high level of neuroticism or low level of resilience, and low family functioning, compared with only member having them, there was a higher risk of poorer dyadic QoL.

\section{Conclusions}

Our study identified the four heterogeneities of dyadic QoL profiles among advanced lung cancer patient-caregiver dyads. Future dyadic interventions should consider the heterogeneity of dyadic QoL in this population and prioritize patient-caregiver dyads who are at risk of poor dyadic QoL. Furthermore, when high neuroticism, low resilience, or family functioning coexist between patients and their caregivers, both parties exhibit much lower dyadic QoL.

\section{Introduction}

In China, lung cancer is the most common cancer and the leading cause of cancer-related deaths. Approximately 810,000 people were newly diagnosed with lung cancer, and 710,000 people died of lung cancer in 2020 [1]. Significantly, the majority of new lung cancer cases are diagnosed at an advanced stage, with $57 \%$ developing distant metastases $[2,3]$.

The challenges or adversities caused by cancer can lead to lower quality of life (QoL) in both patients and their caregivers. As lung cancer and its treatment have negative effects on both the patients and their caregivers, the main focus of cancer care and its research has shifted from the individual to the dyadic level of patient-caregiver dyads [4]. Furthermore, the interdependence theory [5] and empirical research have confirmed the interdependence of QoL in patient-caregiver dyads, calling for treating the patient-caregiver dyad as a unit both conceptually and methodologically $[6,7]$.

The traditional method of studying dyadic QoL is a variable-centered approach, which is useful for clarifying associations among variables and unraveling contributors to specific QoL outcomes but is limited in terms of capturing the heterogeneity in QoL within patient-caregiver dyads [8]. For example, research using global indicators of QoL found that patients had a lower QoL than their caregivers [9, 10]; however, it seems unsuitable as it arbitrarily regards all patients as having poorer QoL than their caregivers. Distinct dyadic QoL profiles among patient-caregiver dyads may be unidentified. Specifically, prior studies indicated that cancer patients and their caregivers experienced positive (e.g., better family closeness and healthier lifestyles) and negative aspects (e.g., disease progress and increasing caregiving demands) in the process of adapting to cancer [11-13], which had different effects on their QoL. However, not each dyad has the same experiences, which leads to variations in specific QoL dimensions across dyads. For instance, Lee and Lyons (2019) found a congruent pattern between patients and caregivers of non-small cell lung cancer, which was characterized by an almost identical moderate mental health in patient-caregiver dyads and a disparate pattern characterized by the better mental health of the patients compared with the caregivers [14]. Increasing evidence $[14,15]$ acknowledges heterogeneity existing across dyads; 
however, the specific profiles of dyadic QoL are still unclear. Identifying the heterogeneity of these dyadic QoL profiles can ascertain vulnerable subgroups, and identify their risk and protective factors.

According to the transactional stress theory [16], personal and environmental characteristics affect an individual's adaptive outcomes (i.e., QoL) when exposed to adversity. Neuroticism, as a crucial personal characteristic, is characterized by more stress, negative emotions, and emotional instability [17]. Accumulative evidence suggests that cancer patients and caregivers with higher neuroticism scores have an increased risk of poor QoL $[18,19]$. Resilience, another important personal characteristic, is defined as the individuals' ability to recover from challenges and major traumatic events [20]. Cancer patients' and caregivers' resilience have been positively linked to their own increased QoL [21, 22]. Family functioning is a crucial environmental protective characteristic [23]. Individuals living in families with positive family functioning are prone to feel loved, accepted, and gain more positive resources, and has been revealed as an important predictor of better QoL among cancer patients and caregivers [24,25]. Given that the above-mentioned personal (i.e., neuroticism, resilience) and environmental characteristics (i.e., family functioning) play important roles in predicting QoL, it is helpful to examine the independent effects of these factors on the distinct dyadic QoL profiles. Additionally, when high neuroticism coexists between patients and their caregivers, both parties are more reactive to stress and emotions, which degrades their QoL. In contrast, when high resilience or family functioning coexists between patients and their caregivers, both parties show positive adaption in the face of adversity or acquire more intra- and extra-family resources for better adaption, which underpins their QoL. The question arises whether there is a higher risk of poorer dyadic QoL profiles when both the patients and caregivers have high levels of neuroticism or low levels of resilience or family functioning, simultaneously, compared with only one party having them. However, a relative dearth of research explored the combined effect of these factors (e.g., the transactional effect of one patient's high resilience and the caregiver's low resilience) on dyadic QoL profiles.

This study aimed to: (1) identify heterogeneity of dyadic QoL profiles among advanced lung cancer patient-caregiver dyads, (2) determine whether these profiles differ in terms of demographic and medical factors, personal characteristics (i.e., neuroticism and resilience), and environmental characteristics (i.e., family functioning); and (3) explore the combined effect of patients' and caregivers' neuroticism, resilience, and family functioning on dyadic QoL profiles.

\section{Methods}

\section{Study design and participants}

A cross-sectional survey was conducted at the departments of radiotherapy and chemotherapy at three tertiary hospitals in Jinan, Shandong Province, China, from March 2019 to February 2020. Patient and caregiver inclusion criteria included: age 18 years or older, fluent in written or spoken Chinese, diagnosed at lung cancer stages III or IV, and caregiver identified by the patient as the primary caregiver. The exclusion criteria included unwillingness to participate in this study, psychiatric disorders, or cognitive disorders. Of the 380 patient-caregiver dyads eligible for the study, 29 refused to participate and 47 failed to complete the questionnaires. Thus, 304 patient-caregiver dyads were included in this study. This study was approved by the university ethics committee and was conducted following the tenets of the Declaration of Helsinki. Informed consent was obtained from all participants included in this study.

\section{Measures}

\section{Neuroticism}

The 8-item Neuroticism subscale of the 44-item Big Five Inventory (BFI) [26] was used to assess neuroticism. Responses were rated on a five-point Likert scale ranging from "strongly disagree" $=1$ to "strongly agree" $=5$. Higher scores were related to higher levels of neuroticism. Cronbach's a for the subscales were 0.79 in patients, and 0.76 in caregivers, respectively.

\section{Resilience}

The 10-item Connor-Davidson Resilience Scale [27] was used to assess resilience. Responses were rated on a five-point Likert scale ranging from "Not true at all" $=0$ to "True almost always" $=4$. Higher scores were associated with greater resilience. Cronbach's a of the questionnaire was 0.93 in patients and 0.92 in caregivers, respectively.

\section{Family functioning}


The General Functioning subscale of the Family Assessment Device [28] was used to assess participants perceived overall functioning of a family system. The 12-item scale was rated on a four-point Likert scale ranging from "strongly disagree" $=1$ to "strongly agree" $=4$. Higher scores reflected greater family functioning. Cronbach's a of the questionnaire was 0.85 in patients and 0.81 in caregivers.

\section{QoL}

The Medical Outcomes Study Short Form-8 Health Survey (SF-8) [29] was used to assess QoL. SF-8 comprises eight dimensions: general health perceptions, physical functioning, physical role, bodily pain, vitality, social functioning, mental health, and emotional role. Responses were rated on a five-point Likert scale. The raw scores were transformed into standard scores of $0-100$, with higher scores associated with better QoL. Cronbach's a of the SF-8 was 0.90 in patients and 0.89 in caregivers, respectively.

\section{Covariates}

The covariates analyzed in the study consisted of demographic and medical characteristics such as advanced lung cancer patients and their caregivers' age, sex, marriage, education, employment status, lung cancer type, Eastern Cooperative Oncology Group (ECOG) performance, caregivers' relationship with patients (see Table 1).

\section{Data analysis}

Latent profile analysis (LPA) is a person-centered approach that determines heterogeneity profiles of dyadic QoL, categorizing them as diverging subgroups that are internally homogeneous [30] based on the patterns of means on observed variables (i.e., the eight dimensions of QoL in this study). The optimal number of profiles was evaluated using model-fit indices, such as the Akaike information criterion (AIC), Bayesian information criterion (BIC), sample-size-adjusted BIC (aBIC), entropy, the Vuong-Lo-Mendell-Rubin likelihood ratio test (LMR), and the bootstrapped likelihood ratio test (BLRT).

After the optimal number of profiles was obtained, the one-way analysis of variance (ANOVA) and chi-square tests were conducted to identify differences in demographic and medical characteristics, neuroticism, resilience, and family functioning among different dyadic QoL profiles. Multinomial logistic regression analysis was conducted to evaluate the unique association of each predictor variable that was significant in the one-way ANOVA or chi-square tests with profile membership. To examine the combined effect, we initially divided the scores of neuroticism, resilience, and family functioning of patients and caregivers into high (above mean) and low (below mean) groups according to the mean split method. Then, we created a new composite variable (e.g., neuroticism) including 4 combinations of the patient neuroticism (high vs. low) and caregiver neuroticism (high vs. low) to further explore the combined effect of patients' and caregivers' neuroticism, resilience and family functioning on dyadic QoL profiles were employed using multinomial logistic regression analysis. Statistical analyses were performed using SPSS 26.0 and Mplus 7.4 with a significance level of $5 \%$ (2-tailed).

\section{Results}

The mean age of the advanced lung cancer patient-caregiver dyads were $58.50(S D=10.11)$ years for patients and $45.47(S D=11.85)$ for caregivers. Table 1 depicts the detailed demographic and medical characteristics.

\section{Latent profile analyses}

To identify the optimal profile solution, LPA models with one to six profiles were estimated (see Table 2). The four-profile solution fitted the data significantly better than the three-profile solution; more specifically, the four-profile solution demonstrated lower values of AIC, BIC, and aBIC, higher entropy than the three-profile solution, and LMR and BLRT became significant when reaching the fourprofile solution. Although the five-profile solution demonstrated lower values of AIC, BIC, and aBIC than the four-profile solution, the nonsignificant $p$ value for LMR further confirmed that the five-profile solution did not significantly improve over the four-profile solution. Additionally, the entropy values in the four-profile solution were the highest, indicating that the four-profile solution provided fair classification accuracy.

Four profiles of dyadic QoL are presented graphically in Fig. 1. In group 1 ( $n=118,38.82 \%)$, labeled as patient low-caregiver high profile, patients reported low levels of QoL, but caregivers reported a higher level of QoL than patients. Group $2(n=68,22.37 \%)$, labeled 
as patient high-caregiver high profile, was characterized by both patients and their caregivers reporting higher levels of QoL relative to the other profiles. In group $3(n=60,19.74 \%)$, labeled as patient high-caregiver low profile, patients reported a comparatively higher level of QoL than their caregivers, who reported low levels of QoL. Group 4 ( $n=58,19.08 \%)$, labeled as patient low-caregiver low profile, was characterized by patients and their caregivers reporting lower levels of QoL compared with the other profiles.

\section{Comparisons of demographic, medical characteristics, neuroticism, resilience, family functioning among the four profiles}

The results showed that patients' economic situation, ECOG performance status, caregivers' age, marriage, economic situation, relationship to the patient, and the neuroticism, resilience, and family functioning of patients and their caregivers significantly differed across the four profiles (see Table 1).

Multinomial logistic regression was further conducted to explore whether the significant variables in the univariate analysis predicted profile membership (Table 3). Considering that no caregivers whose marital status was single/divorced/widowed were classified into a patient low-caregiver low profile, marriage was omitted from further analyses. The patient high-caregiver high profile was used as the reference group. Patients whose economic situation was income lesser than the expenditure $(\mathrm{OR}=5.943 ; p=0.006)$ were more likely to belong to the patient low-caregiver high profile compared to those with income more than the expenditure. Patients with higher scores on ECOG performance status and neuroticism were associated with increased odds of membership to the patient lowcaregiver high profile and patient low-caregiver low profile. Elderly caregivers $(\mathrm{OR}=1.067 ; p=0.015)$ were more likely to be categorized as having a patient high-caregiver low profile. Moreover, caregivers with low resilience tended to have increased odds of belonging to the patient high-caregiver low and patient low-caregiver low profiles. Patients with high family functioning were more likely to be categorized as a patient high-caregiver low profile.

\section{Combined Effect of patient neuroticism, resilience, family functioning and caregiver neuroticism, resilience, family functioning associated with distinct dyadic QoL profiles}

As Table 4 shows, the subgroup of patient high neuroticism-caregiver low neuroticism was 3.21 times more likely to belong to the patient low-caregiver high profile compared to the dyads of patient low neuroticism-caregiver low neuroticism. The subgroup of patients and their caregivers who both had high neuroticism was 3.92 times more likely to be classified as the patient high-caregiver low profile. The subgroups of patient low neuroticism-caregiver high neuroticism, patient high neuroticism-caregiver low neuroticism, and patient high neuroticism-caregiver high neuroticism had 4.247, 9.167, and 10.869 times the likelihood of belonging to the patient low-caregiver low profile, respectively. That is, both the patients and their caregivers with a high level of neuroticism simultaneously had a higher likelihood of belonging to the patient low-caregiver low profile, compared with only one member with high neuroticism.

Furthermore, compared to patient high resilience-caregiver high resilience, the subgroup of patient low resilience-caregiver high resilience and patient low resilience-caregiver low resilience were $2.727,7.271$ times respectively more likely to belong to the patient low-caregiver high profile. In addition, the subgroup of patient high resilience-caregiver low resilience and the subgroup of patients and their caregivers with low resilience were 4.088, 8.620 times more likely to belong to the patient high-caregiver low profile, respectively. Finally, the subgroup of patient high resilience-caregiver low resilience was 4.311 times more likely to belong to the patient lowcaregiver low profile, and the subgroup of patient low resilience-caregiver low resilience was 11.340 times more likely to belong to the patient low-caregiver low profile. Therefore, the dyads of both patients and their caregivers with low resilience increased their likelihood of belonging to the patient low-caregiver low profile than only one party with low resilience $(O R=11.340 \mathrm{vs}$. OR $=4.311$ vs.

$O R=2.223$ ). One interesting finding is that only caregivers with lower resilience were found to be at a higher likelihood of being classified in the patient low-caregiver low profile than only patients with lower resilience $(\mathrm{OR}=4.311, P=0.013$ vs. $\mathrm{OR}=2.223, P=$ 0.173).

As for the combined effect of family functioning, the odds of both patients and their caregivers with low family functioning being classified in the patient high-caregiver low and patient low-caregiver low profiles were 5.453 and 2.944 times, respectively.

\section{Discussion}

This study utilized a person-centered approach (i.e., LPA) to capture the heterogeneity of dyadic QoL profiles and explored their associations with different characteristics among advanced lung cancer patients and their caregivers. 
Our findings revealed four dyadic QoL profiles. First, most advanced lung cancer patient-caregiver dyads ( $n=118,38.82 \%$ ) were divided into patient low-caregiver high profile, in which patients scored low, but caregivers scored high on the QoL indicators. This result is expected, given that most prior researchers have found worse QoL among cancer patients than their caregivers $[9,10,31]$. Second, a patient high-caregiver high profile was observed. Third, an important and interesting finding is the existence of such a patient highcaregiver low profile characterized by patients scoring high on the QoL indicators, but caregivers scoring low on the QoL indicators. This finding is difficult to trace using the traditional variable-centered approach and suggests that clinical practitioners should pay more attention to this vulnerable profile, especially the caregivers, because of lower QoL. Fourth, a patient low-caregiver low profile was also identified. The heterogeneity of dyadic QoL profiles highlights the importance of adopting tailored dyadic interventions, rather than taking on a "one-size-fits-all" approach. For instance, the dyads in patient low-caregiver high profile may benefit from adopting a patient-focused, caregiver-assisted dyadic intervention. The dyads in patient low-caregiver low profile may benefit from adopting both patient and caregiver focused dyadic intervention. Future research could explore the effectiveness of personalized dyadic interventions in heterogeneous profiles.

The demographic and medical characteristics of the dyadic QoL profiles differed. Specifically, patients with higher financial burdens had an increased likelihood of belonging to the patient low-caregiver high profile. A study indicated that $72.68 \%$ of lung cancer patients reported catastrophic health-related spending, and $37 \%$ reported healthcare costs exceeding the annual household income [32]. Our results revealed that $70.06 \%$ of the patients had incomes less than their expenditures. The association between high financial burden and poor QoL in this study is consistent with prior research [33]. Patients with higher scores of ECOG performance status were more likely to belong to the patient low-caregiver high profile and patient low-caregiver low profile. Cancer patients with higher scores on ECOG performance status have more difficulty in completing daily living activities and therefore experience QoL deterioration [34]. Older caregivers were more likely to belong to the patient high-caregiver low profile. This may be owing to elderly caregivers' decline in physical health (e.g., degenerative changes), which is also associated with lower QoL [35, 36].

Patients in the patient low-caregiver high profile and patient low-caregiver low profile were more neurotic. Unsurprisingly, a person with high neuroticism may regard the diagnosis of cancer as more threatening or severe, have more negative health perception, and will thus report lower QoL $[17,18,37]$. Caregivers with low resilience were more likely to be classified in the patient high-caregiver low and patient low-caregiver low profiles. Resilience is a critical psychological asset that embodies the personal qualities needed for individuals to thrive in the face of adversity $[38,39]$. Caregivers with low resilience tended not to utilize the resources to adapt to the adversity they encountered, thereby decreasing their QoL. Moreover, patients who perceived better family functioning were more likely to be included in the patient high-caregiver low profile. Patients with better family functioning perceived a strong emotional bonding with their family and could acquire more support from family members, which led to better QoL, which was consistent with prior work [24].

This study found that the dyads of both patients and caregivers with high neuroticism were associated with the highest odds of belonging to the patient low-caregiver low profile, followed by the dyads of only patients with high neuroticism, and the dyads of only caregivers with high neuroticism. This finding indicated that both the patients and their caregivers with a high level of neuroticism simultaneously had lower dyadic QoL, compared with only one of the dyads being neurotic. Additionally, the dyads of only patients with high neuroticism were found to be at a higher likelihood for being classified in the patient low-caregiver low profile than the dyads of only caregivers with high neuroticism. Patients with advanced lung cancer and their caregivers are inclined to react as emotional units. Patients' neuroticism has a negative effect on their own QoL, as does spillover on their caregivers' QoL [40]. In this study, compared to caregivers' neuroticism, patients' neuroticism generated greater spillover effects on the QoL of patient-caregiver dyads.

An interesting finding was that only caregivers with lower resilience showed a higher likelihood of belonging to the patient lowcaregiver low profile than only patients with low resilience. Caregivers' heavy caregiving tasks (e.g., form treatment regimens, and manage medications) place high demands on their physical and emotional reserves, and resilience not only helps them facilitate the caregiving task but transmits from them to the patients through information exchange, and communication. [38, 41]. Moreover, both patients and caregivers with low resilience showed the highest risk of reducing dyadic QoL compared with only one of the dyads with low resilience. This finding suggests that identifying the dyads of both patients and caregivers with low resilience may be conducive to implementing preventive interventions to mitigate their higher risk of poor QoL.

Furthermore, patients and caregivers with low family functioning were more likely to belong to the patient high-caregiver low profile or patient low-caregiver low profile. A previous study suggested that patients' perceived family functioning may be different from that of their caregivers, even though they belonged to the same family $[41,42]$. Thus, assessing family functioning from the perspectives of

Page 6/16 
both patients and their caregivers could truly reflect the functioning of the family [43]. Both patients and caregivers in this study reported poorer family functioning, which was related to ineffective communication patterns and poor health-related behaviors (e.g., physical activity, screening physical examination), thus reducing their QoL.

This study has certain limitations. First, causal directionality needs to be cautiously interpreted with this cross-sectional design. Second, this study focused on modifiable psychological variables that could be addressed through an intervention. However, several factors (e.g., symptom distress, caregiver burden, and coping strategy) that can predict dyadic QoL were not included. Future research should incorporate these factors to develop a robust predictive model of dyadic QoL. Third, this study assessed participants' perceived family functioning rather than objective family functioning. However, this study assessed family functioning from multiple perspectives and greatly reduced the error. Future studies are recommended to specify extended or nuclear families when assessing family functioning.

\section{Conclusion}

This study captured the four heterogeneities of dyadic QoL profiles among advanced lung cancer patient-caregiver dyads and explore their influencing factors. Future dyadic interventions should consider the heterogeneity of dyadic QoL in this population and prioritize patient-caregiver dyads who are at risk of poor dyadic QoL. Furthermore, when high neuroticism, low resilience, or family functioning coexist between patients and their caregivers, both parties exhibit much lower dyadic QoL.

\section{Declarations}

Acknowledgements: This study was funded by Young Scholars Program of Shandong University (grant number: 2017WLJH42). The authors would like to thank all the participants in this study. This study could have not been completed without their support.

Author contributions: Hui Wang: conceptualization, investigation, methodology, writing original draft; Tiantian Deng: conceptualization, investigation, methodology, writing-review; Cong Cao: conceptualization, methodology, writing-review; Danjun Feng: funding acquisition, conceptualization, methodology, supervision. All the authors have read and approved the final version of the manuscript.

Data availability: The data of this study can be available from the corresponding author.

Code availability: N/A.

Ethical approval: This study was approved by the ethics review board of the School of Nursing at Shandong University and was conducted following tenets of the Declaration of Helsinki.

Consent to participate: Informed consent was obtained from all participants included in this study.

Consent for publication All of the authors approved the final paper for publication.

Conflicts of interest: The authors have no relevant financial or non-financial interests to disclose.

\section{References}

1. World Health Organization (2021) China - The global cancer observatory. https:// gco.iarc.fr/ today/data/factsheets/populations/160-china-fact-sheets.pdf

2. Reale ML, Di Maio M (2020) Quality of life in patients with lung cancer: The way forward. Lancet Oncol 21(5):617-619. http://doi.org/10.1016/S1470-2045(20)30151-0

3. Cancer Statistics Review (2020) Previous version: SEER cancer statistics review, 1975-2012. https://seer.cancer.gov/archive/csr/1975_2012/

4. Luo X, Gao L, Li J, Lin Y, Zhao J, Li Q (2019) A critical literature review of dyadic web-based interventions to support cancer patients and their caregivers, and directions for future research. Psycho-oncology 29(1):38-48. http://doi.org/10.1002/pon.5278

5. Kelley HH, Thibaut JW (1978) Interpersonal relations: A theory of interdependence. Wiley 
6. Streck BP, Wardell DW, LoBiondo-Wood G, Beauchamp JES (2020) Interdependence of physical and psychological morbidity among patients with cancer and family caregivers: Review of the literature. Psycho-oncology 29(6):974-989.

http://doi.org/10.1002/pon.5382

7. Lyons KS, Lee CS (2020) The association of dyadic symptom appraisal with physical and mental health over time in care dyads living with lung cancer. J Fam Nurs 26(1):15-25. http://doi.org/10.1177/1074840719889967

8. Bauer D, Shanahan M (2007) Modeling complex interactions: Person-centered and variable-centered approaches. In: Little T, Bovaird J, Card NA (eds) Modeling contextual effects in longitudinal studies. Erlbaum, pp 255-284

9. Li Q, Xu Y, Zhou H, Loke AY (2016) Factors influencing the health-related quality of life of Chinese advanced cancer patients and their spousal caregivers: A cross-sectional study. BMC Palliative Care 15(1):72. http://doi.org/10.1186/s12904-016-0142-3

10. Abdullah NN, Idris IB, Shamsuddin K, Abdullah NMA (2020) Health-related quality of life in Malaysian gastrointestinal cancer patients and their family caregivers-a comparison study. Supportive Care in Cancer: Official Journal of the Multinational Association of Supportive Care in Cancer 28(4):1891-1899. http://doi.org/10.1007/s00520-019-05007-5

11. Li Q, Chiang VCL, Xu X, Xu Y, Loke AY (2015) The experiences of Chinese couples living with cancer: A Focus Group Study. Cancer Nurs 38(5):383-394. http://doi.org/10.1097/NCC.0000000000000196

12. Yu DSF, Cheng ST, Wang J (2018) Unravelling positive aspects of caregiving in dementia: An integrative review of research literature. Int J Nurs Stud 79:1-26. http://doi.org/10.1016/j.ijnurstu.2017.10.008

13. Galvin M, Gavin T, Mays I, Heverin M, Hardiman O (2020) Individual quality of life in spousal ALS patient-caregiver dyads. Health Qual Life Outcomes 18(1):371. http://doi.org/10.1186/s12955-020-01551-5

14. Lee CS, Lyons KS (2019) Patterns, relevance, and predictors of dyadic mental health over time in lung cancer. Psycho-oncology 28(8):1721-1727. http://doi.org/10.1002/pon.5153

15. Lyons KS, Lee CS (2018) The theory of dyadic illness management. J Fam Nurs 24(1):8-28. http://doi.org/10.1177/1074840717745669

16. Lazarus RS, Folkman S (1984) Stress, appraisal, and coping. Springer

17. Macía P, Gorbeña S, Gómez A, Barranco M, Iraurgi I (2020) Role of neuroticism and extraversion in the emotional health of people with cancer. Heliyon 6(7):e04281. http://doi.org/10.1016/j.heliyon.2020.e04281

18. Dunne S, Mooney O, Coffey L, Sharp L, Desmond D, Timon C et al (2017) Psychological variables associated with quality of life following primary treatment for head and neck cancer: A systematic review of the literature from 2004 to 2015. Psycho-oncology 26(2):149-160. http://doi.org/10.1002/pon.4109

19. Kim SK, Park M, Lee Y, Choi SH, Moon SY, Seo SW et al (2017) Influence of personality on depression, burden, and health-related quality of life in family caregivers of persons with dementia. Int Psychogeriatr 29(2):227-237. http://doi.org/10.1017/S1041610216001770

20. Carver CS (1998) Resilience and thriving: Issues, models, and linkages. J Soc Issues 54(2):245-266. http://doi.org/10.1111/0022-4537.641998064

21. Tian J, Hong JS (2014) Assessment of the relationship between resilience and quality of life in patients with digestive cancer. World J Gastroenterol 20(48):18439-18444. http://doi.org/10.3748/wjg.v20.i48.18439

22. Üzar-Özçeti NYS, Dursun S (2020) Quality of life, caregiver burden, and resilience among the family caregivers of cancer survivors. European Journal of Oncology Nursing 48:101832. http://doi.org/10.1016/j.ejon.2020.101832

23. Li C, Lu H, Qin W, Li X, Yu J, Fang F (2019) Resilience and its predictors among Chinese liver cancer patients undergoing transarterial chemoembolization. Cancer Nurs 42(5):E1-E9. http://doi.org/10.1097/NCC.0000000000000640

24. Kołtuniuk A, Rozensztrauch A, Budzińska P, Rosińczuk J (2019) The quality of life of Polish children with cerebral palsy and the impact of the disease on the family functioning. J Pediatr Nurs 47:e75-e82. http://doi.org/10.1016/j.pedn.2019.05.011

25. Lim JW, Ashing-Giwa KT (2013) Is family functioning and communication associated with health-related quality of life for Chinese- and Korean-American breast cancer survivors? Quality of Life Research: An International Journal of Quality of Life Aspects of Treatment, Care and Rehabilitation 22(6):1319-1329. http://doi.org/10.1007/s11136-012-0247-y

26. Carciofo R, Yang J, Song N, Du F, Zhang K (2016) Psychometric evaluation of Chinese-language 44-item and 10-item big five personality inventories, including correlations with chronotype, mindfulness and mind wandering. PLoS ONE 11(2):e0149963. http://doi.org/10.1371/journal.pone.0149963 
27. Wang L, Shi Z, Zhang Y, Zhang Z (2010) Psychometric properties of the 10-item Connor-Davidson Resilience Scale in Chinese earthquake victims. J Neuropsychiatry Clin Neurosci 64(5):499-504. http://doi.org/10.1111/j.1440-1819.2010.02130.x

28. Liu P, He M (1999) Family assessment device, FAD. In: Wang X, Wang X, Ma H (eds) Handbook of Mental Health Rating Scales (Supplement. Chinese Mental Health Journal, pp 149-152

29. Wang S, Luan R, Lei Y, Kuang C, He C, Chen Y (2007) Development and evaluation of Chinese version of short form 8. Modern Prevention Medicine 34(6):1022-1023. https://doi.org/10.3969/j.issn.1003-8507.2007.06.009

30. Schnettler B, Grunert KG, Orellana L, Miranda H, Lobos G, Miranda-Zapata E et al (2021) The diverging patterns of life satisfaction between families: A latent profile analysis in dual-earner parents with adolescents. Current Psychology (Advance online publication) http://doi.org/10.1007/s12144-020-01316-9

31. Lin Y, Hu C, Xu Y, Zhao J, Li Q (2020) The mutual impact and moderating factors of quality of life between advanced cancer patients and their family caregivers. Supportive Care in Cancer: Official Journal of the Multinational Association of Supportive Care in Cancer 28(11):5251-5262. http://doi.org/10.1007/s00520-020-05351-x

32. Chen JE, Lou VW, Jian H, Zhou Z, Yan M, Zhu J et al (2018) Objective and subjective financial burden and its associations with health-related quality of life among lung cancer patients. Supportive Care in Cancer: Official Journal of the Multinational Association of Supportive Care in Cancer 26(4):1265-1272. http://doi.org/10.1007/s00520-017-3949-4

33. Lathan CS, Cronin A, Tucker-Seeley R, Zafar SY, Ayanian JZ, Schrag D (2016) Association of financial strain with symptom burden and quality of life for patients with lung or colorectal cancer. Journal of Clinical Oncology: Official Journal of the American Society of Clinical Oncology 34(15):1732-1740. http://doi.org/10.1200/JC0.2015.63.2232

34. Laird BJA, Fallon M, Hjermstad MJ, Tuck S, Kaasa S, Klepstad P et al (2016) Quality of life in patients with advanced cancer: Differential association with performance status and systemic inflammatory response. Journal of Clinical Oncology: Official Journal of the American Society of Clinical Oncology 34(23):2769-2775. http://doi.org/10.1200/JC0.2015.65.7742

35. Hsu T, Nathwani N, Loscalzo M, Chung V, Chao J, Karanes C et al (2019) Understanding caregiver quality of life in caregivers of hospitalized older adults with cancer. J Am Geriatr Soc 67(5):978-986. http://doi.org/10.1111/jgs.15841

36. Ma Y, He B, Jiang M, Yang Y, Wang C, Huang C et al (2020) Prevalence and risk factors of cancer-related fatigue: A systematic review and meta-analysis. Int J Nurs Stud 111:103707. http://doi.org/10.1016/j.ijnurstu.2020.103707

37. Lahey BB (2009) Public health significance of neuroticism. Am Psychol 64(4):241-256. http://doi.org/10.1037/a0015309

38. Zhang J, Yu NX, Zhou M, Zhang J (2017) Dyadic effects of resilience on well-being in Chinese older couples: Mediating role of spousal support. Journal of Family Psychology: JFP: Journal of the Division of Family Psychology of the American Psychological Association 31(3):273-281. http://doi.org/10.1037/fam0000250

39. Connor KM, Davidson JRT (2003) Development of a new resilience scale: The Connor-Davidson Resilience Scale (CD-RISC). Depress Anxiety 18(2):76-82. http://doi.org/10.1002/da.10113

40. Lim JW, Shon EJ (2018) The dyadic effects of family cohesion and communication on health-related quality of life: The moderating role of sex. Cancer Nurs 41(2):156-165. http://doi.org/10.1097/NCC.0000000000000468

41. Wang $H$, Yue H, Ren M, Feng D (2021) Dyadic effects of family-functioning and resilience on quality of life in advanced lung cancer patients and caregivers: An actor-partner interdependence mediation model. European Journal of Oncology Nursing: The Official Journal of European Oncology Nursing Society 52:101963. http://doi.org/10.1016/j.ejon.2021.101963

42. Shin DW, Shin J, Kim SY, Yang HK, Cho J, Youm JH et al (2016) Family avoidance of communication about cancer: A dyadic examination. Cancer Research and Treatment 48(1):384-392. http://doi.org/10.4143/crt.2014.280

43. Li Y, Wang K, Yin Y, Li Y, Li S (2018) Relationships between family resilience, breast cancer survivors' individual resilience, and caregiver burden: A cross-sectional study. Int J Nurs Stud 88:79-84. http://doi.org/10.1016/j.ijnurstu.2018.08.011

\section{Tables}


Table 1

Demographic, medical characteristics, neuroticism, resilience, and family functioning of four latent profiles

\begin{tabular}{|c|c|c|c|c|c|c|}
\hline & All sample & $\begin{array}{l}\text { Patient low- } \\
\text { caregiver low } \\
\text { profile }\end{array}$ & $\begin{array}{l}\text { Patient low- } \\
\text { caregiver high } \\
\text { profile }\end{array}$ & $\begin{array}{l}\text { Patient high- } \\
\text { caregiver low } \\
\text { profile }\end{array}$ & $\begin{array}{l}\text { Patient high- } \\
\text { caregiver } \\
\text { high profile }\end{array}$ & $\begin{array}{l}P \\
\text { value }\end{array}$ \\
\hline \multicolumn{7}{|l|}{ Patients } \\
\hline Sex & & & & & & 0.608 \\
\hline Male & $203(66.8 \%)$ & $35(60.3 \%)$ & $78(66.1 \%)$ & $42(70.0 \%)$ & $48(70.6 \%)$ & \\
\hline Female & $101(33.2 \%)$ & $23(39.7 \%)$ & $40(33.9 \%)$ & $18(30.0 \%)$ & $20(29.4 \%)$ & \\
\hline Age (Mean $\pm S D)$ & $58.50 \pm 10.11$ & $56.57 \pm 11.09$ & $58.75 \pm 11.03$ & $59.44 \pm 7.56$ & $58.91 \pm 9.48$ & 0.423 \\
\hline Education & & & & & & 0.941 \\
\hline Illiterate & $33(10.9 \%)$ & $8(13.8 \%)$ & $13(11.0 \%)$ & $5(8.3 \%)$ & $7(10.3 \%)$ & \\
\hline Primary school & $54(17.8 \%)$ & $8(13.8 \%)$ & $26(22.0 \%)$ & $9(15.0 \%)$ & $11(16.2 \%)$ & \\
\hline Junior high school & 103(33.9\%) & $22(37.9 \%)$ & $36(30.5 \%)$ & $23(38.3 \%)$ & $22(32.4 \%)$ & \\
\hline $\begin{array}{l}\text { High school/vocational } \\
\text { high school }\end{array}$ & $67(22.0 \%)$ & $10(17.2 \%)$ & $25(21.2 \%)$ & $15(25.0 \%)$ & $17(25.0 \%)$ & \\
\hline University and college & $47(15.5 \%)$ & $10(17.2 \%)$ & $18(15.3 \%)$ & $8(13.3 \%)$ & $11(16.2 \%)$ & \\
\hline Marital Status ${ }^{a}$ & & & & & & 0.587 \\
\hline Married & $290(95.4 \%)$ & $54(93.1 \%)$ & $113(95.8 \%)$ & $58(98.3 \%)$ & $65(95.6 \%)$ & \\
\hline Single/divorced/widowed & $13(4.3 \%)$ & $4(6.9 \%)$ & $5(4.2 \%)$ & $1(1.7 \%)$ & $3(4.4 \%)$ & \\
\hline Current work status & & & & & & 0.557 \\
\hline Employed & $61(20.1 \%)$ & $11(19.0 \%)$ & $21(17.8 \%)$ & $12(20.0 \%)$ & $17(25.0 \%)$ & \\
\hline Unemployed & $153(50.3 \%)$ & $35(60.3 \%)$ & $59(50.0 \%)$ & $28(46.7 \%)$ & $31(45.6 \%)$ & \\
\hline Retired & $90(29.6 \%)$ & $12(20.7 \%)$ & $38(32.2 \%)$ & $20(33.3 \%)$ & $20(29.4 \%)$ & \\
\hline Economic situation ${ }^{a}$ & & & & & & $<0.001$ \\
\hline $\begin{array}{l}\text { Income lesser than the } \\
\text { expenditure }\end{array}$ & $213(70.1 \%)$ & $43(74.1 \%)$ & $94(79.7 \%)$ & $42(71.2 \%)$ & $34(50.0 \%)$ & \\
\hline $\begin{array}{l}\text { Income equal to the } \\
\text { expenditure }\end{array}$ & $60(19.7 \%)$ & $14(24.1 \%)$ & $17(14.4 \%)$ & $7(11.9 \%)$ & $22(32.4 \%)$ & \\
\hline $\begin{array}{l}\text { Income more than the } \\
\text { expenditure }\end{array}$ & $30(9.9 \%)$ & $1(1.7 \%)$ & $7(5.9 \%)$ & $10(16.9 \%)$ & $12(17.6 \%)$ & \\
\hline $\begin{array}{l}\text { Clinical Tumour-Node- } \\
\text { Metastasis stage }\end{array}$ & & & & & & 0.191 \\
\hline III & $99(32.6 \%)$ & $15(25.9 \%)$ & $34(28.8 \%)$ & $25(41.7 \%)$ & $25(36.8 \%)$ & \\
\hline IV & $205(67.4 \%)$ & $43(74.1 \%)$ & $84(71.2 \%)$ & $35(58.3 \%)$ & $43(63.2 \%)$ & \\
\hline Lung cancer type ${ }^{a}$ & & & & & & 0.114 \\
\hline Small cell carcinoma & $79(26.0 \%)$ & $13(22.4 \%)$ & $35(29.9 \%)$ & $13(21.7 \%)$ & $18(26.5 \%)$ & \\
\hline $\begin{array}{l}\text { Squamous cell } \\
\text { carcinoma }\end{array}$ & $46(15.1 \%)$ & $11(19.0 \%)$ & $11(9.4 \%)$ & $13(21.7 \%)$ & $11(16.2 \%)$ & \\
\hline Note. ECOG: Eastern Coope & tive Oncolog & roup & & & & \\
\hline
\end{tabular}




\begin{tabular}{|c|c|c|c|c|c|c|}
\hline & All sample & $\begin{array}{l}\text { Patient low- } \\
\text { caregiver low } \\
\text { profile }\end{array}$ & $\begin{array}{l}\text { Patient low- } \\
\text { caregiver high } \\
\text { profile }\end{array}$ & $\begin{array}{l}\text { Patient high- } \\
\text { caregiver low } \\
\text { profile }\end{array}$ & $\begin{array}{l}\text { Patient high- } \\
\text { caregiver } \\
\text { high profile }\end{array}$ & $\begin{array}{l}P \\
\text { value }\end{array}$ \\
\hline Adenocarcinoma & $174(57.2 \%)$ & $33(56.9 \%)$ & $71(60.7 \%)$ & $31(51.7 \%)$ & $39(57.4 \%)$ & \\
\hline Large cell carcinoma & $2(0.7 \%)$ & $0(0.0 \%)$ & $0(0.0 \%)$ & $2(3.3 \%)$ & $0(0.0 \%)$ & \\
\hline $\begin{array}{l}\text { Adeno-squamous } \\
\text { carcinoma }\end{array}$ & $2(0.7 \%)$ & $1(1.7 \%)$ & $0(0.0 \%)$ & $1(1.7 \%)$ & $0(0.0 \%)$ & \\
\hline Chemotherapy ${ }^{a}$ & & & & & & 0.112 \\
\hline Yes & $230(75.7 \%)$ & $39(67.2 \%)$ & $86(73.5 \%)$ & $50(83.3 \%)$ & $55(82.1 \%)$ & \\
\hline No & $72(23.7 \%)$ & $19(32.8 \%)$ & $31(26.5 \%)$ & $10(16.7 \%)$ & $12(17.9 \%)$ & \\
\hline Radiotherapy a & & & & & & 0.198 \\
\hline Yes & $23(7.6 \%)$ & $8(13.8 \%)$ & $9(7.7 \%)$ & $3(5.0 \%)$ & $3(4.5 \%)$ & \\
\hline No & $279(91.8 \%)$ & $50(86.2 \%)$ & 108(92.3\%) & $57(95.0 \%)$ & $64(95.5 \%)$ & \\
\hline Targeted-therapy ${ }^{a}$ & & & & & & 0.381 \\
\hline Yes & $81(26.6 \%)$ & $12(20.7 \%)$ & $35(29.9 \%)$ & 19(31.7\%) & $15(22.4 \%)$ & \\
\hline No & $221(72.7 \%)$ & $46(79.3 \%)$ & $82(70.1 \%)$ & $41(68.3 \%)$ & $52(77.6 \%)$ & \\
\hline Immunotherapy ${ }^{\mathrm{a}}$ & & & & & & 0.565 \\
\hline Yes & $17(5.6 \%)$ & $5(8.6 \%)$ & $6(5.1 \%)$ & $4(6.7 \%)$ & $2(3.0 \%)$ & \\
\hline No & 285(93.8\%) & $53(91.4 \%)$ & $111(94.9 \%)$ & $56(93.3 \%)$ & $65(97.0 \%)$ & \\
\hline Supportive care ${ }^{a}$ & & & & & & 0.443 \\
\hline Yes & $45(14.8 \%)$ & $12(20.7 \%)$ & $17(14.5 \%)$ & $6(10.0 \%)$ & $10(14.9 \%)$ & \\
\hline No & $257(84.5 \%)$ & $46(79.3 \%)$ & $100(85.5 \%)$ & $54(90.0 \%)$ & $57(85.1 \%)$ & \\
\hline Time since diagnosis & & & & & & 0.700 \\
\hline$\leq 3$ month & $137(45.1 \%)$ & $22(37.9 \%)$ & $55(46.6 \%)$ & $25(41.7 \%)$ & $35(51.5 \%)$ & \\
\hline 3-6 month & $45(14.8 \%)$ & $13(22.4 \%)$ & $13(11.0 \%)$ & $11(18.3 \%)$ & $8(11.8 \%)$ & \\
\hline 6-12 month & $49(16.1 \%)$ & $9(15.5 \%)$ & $20(16.9 \%)$ & $9(15.0 \%)$ & $11(16.2 \%)$ & \\
\hline$\geq 1$ year & $73(24.0 \%)$ & $14(24.1 \%)$ & $30(25.4 \%)$ & $15(25.0 \%)$ & $14(20.6 \%)$ & \\
\hline Physical Comorbidity ${ }^{a}$ & & & & & & 0.746 \\
\hline Yes & $152(50.0 \%)$ & $29(50.0 \%)$ & $57(49.1 \%)$ & $28(46.7 \%)$ & $38(55.9 \%)$ & \\
\hline No & $150(49.3 \%)$ & $29(50.0 \%)_{-}$ & $59(50.9 \%)$ & $32(53.3 \%)$ & $30(44.1 \%)$ & \\
\hline Smoking ${ }^{a}$ & & & & & & 0.461 \\
\hline Yes & $152(50.0 \%)$ & $28(48.3 \%)$ & $54(47.4 \%)$ & $34(59.6 \%)$ & $36(52.9 \%)$ & \\
\hline No & $145(47.7 \%)$ & $30(51.7 \%)$ & $60(52.6 \%)$ & $23(40.4 \%)$ & $32(47.1 \%)$ & \\
\hline $\begin{array}{l}\text { ECOG performance } \\
\text { status }\end{array}$ & $1.82 \pm 1.00$ & $2.14 \pm 1.10$ & $2.03 \pm 0.99$ & $1.57 \pm 0.93$ & $1.38 \pm 0.81$ & $<0.001$ \\
\hline
\end{tabular}

Note. ECOG: Eastern Cooperative Oncology Group

a implies that the numbers/percentages may not account to the total, due to missing data. 


\begin{tabular}{|c|c|c|c|c|c|c|}
\hline & All sample & $\begin{array}{l}\text { Patient low- } \\
\text { caregiver low } \\
\text { profile }\end{array}$ & $\begin{array}{l}\text { Patient low- } \\
\text { caregiver high } \\
\text { profile }\end{array}$ & $\begin{array}{l}\text { Patient high- } \\
\text { caregiver low } \\
\text { profile }\end{array}$ & $\begin{array}{l}\text { Patient high- } \\
\text { caregiver } \\
\text { high profile }\end{array}$ & $\begin{array}{l}P \\
\text { value }\end{array}$ \\
\hline Neuroticism & $21.30 \pm 6.17$ & $23.25 \pm 5.86$ & $22.23 \pm 5.99$ & $21.05 \pm 5.71$ & $18.25 \pm 6.10$ & $<0.001$ \\
\hline Resilience & $26.90 \pm 7.72$ & $25.40 \pm 7.74$ & $25.16 \pm 7.76$ & $28.26 \pm 6.39$ & $30.00 \pm 7.65$ & $<0.001$ \\
\hline Family functioning & $35.61 \pm 6.02$ & $34.91 \pm 6.89$ & $35.60 \pm 5.78$ & $34.31 \pm 5.88$ & $37.35 \pm 5.46$ & 0.025 \\
\hline \multicolumn{7}{|l|}{ Caregivers } \\
\hline Sex & & & & & & 0.375 \\
\hline Male & $164(53.9 \%)$ & $34(58.6 \%)$ & $63(53.4 \%)$ & $27(45.0 \%)$ & $40(58.8 \%)$ & \\
\hline Female & $140(46.1 \%)$ & $24(41.4 \%)$ & $55(46.6 \%)$ & $33(55.0 \%)$ & $28(41.2 \%)$ & \\
\hline Age (Mean $\pm S D)$ & $45.47 \pm 11.85$ & $46.86 \pm 10.25$ & $45.16 \pm 11.83$ & $48.67 \pm 12.28$ & $41.96 \pm 12.06$ & 0.010 \\
\hline Education & & & & & & 0.543 \\
\hline Illiterate & $10(3.3 \%)$ & $3(5.2 \%)$ & $4(3.4 \%)$ & $2(3.3 \%)$ & $1(1.5 \%)$ & \\
\hline Primary school & $27(8.9 \%)$ & $5(8.6 \%)$ & $13(11.0 \%)$ & $6(10.0 \%)$ & $3(4.4 \%)$ & \\
\hline Junior high school & $81(26.6 \%)$ & $18(31.0 \%)$ & $26(22.0 \%)$ & $20(33.3 \%)$ & $17(25.0 \%)$ & \\
\hline $\begin{array}{l}\text { High school/ vocational } \\
\text { high school }\end{array}$ & $93(30.6 \%)$ & $20(34.5 \%)$ & $38(32.2 \%)$ & $15(25.0 \%)$ & $20(29.4 \%)$ & \\
\hline University and college & $93(30.6 \%)$ & $12(20.7 \%)$ & $37(31.4 \%)$ & $17(28.3 \%)$ & $27(39.7 \%)$ & \\
\hline Marital status ${ }^{a}$ & & & & & & 0.022 \\
\hline Married & 284(93.4\%) & $58(100.0 \%)$ & $110(94.0 \%)$ & $57(95.0 \%)$ & $59(86.8 \%)$ & \\
\hline Single/divorced/widowed & $19(6.3 \%)$ & $0(0.0 \%)$ & $7(6.0 \%)$ & $3(5.0 \%)$ & $9(13.2 \%)$ & \\
\hline Current work status & & & & & & 0.131 \\
\hline Employed & $156(51.3 \%)$ & $27(46.6 \%)$ & $65(55.1 \%)$ & $22(36.7 \%)$ & $42(61.8 \%)$ & \\
\hline Unemployed & $105(34.5 \%)$ & $21(36.2 \%)$ & $39(33.1 \%)$ & $26(43.3 \%)$ & $19(27.9 \%)$ & \\
\hline Retired & $43(14.1 \%)$ & $10(17.2 \%)$ & $14(11.9 \%)$ & $12(20.0 \%)$ & $7(10.3 \%)$ & \\
\hline Economic situation $^{a}$ & & & & & & 0.009 \\
\hline $\begin{array}{l}\text { Income lesser than the } \\
\text { expenditure }\end{array}$ & $170(55.9 \%)$ & $40(69.0 \%)$ & $66(56.4 \%)$ & $39(65.0 \%)$ & $25(37.3 \%)$ & \\
\hline $\begin{array}{l}\text { Income equal to the } \\
\text { expenditure }\end{array}$ & $85(28.0 \%)$ & $14(24.1 \%)$ & $32(27.4 \%)$ & $14(23.3 \%)$ & $25(37.3 \%)$ & \\
\hline $\begin{array}{l}\text { Income more than the } \\
\text { expenditure }\end{array}$ & $47(15.5 \%)$ & $4(6.9 \%)$ & $19(16.2 \%)$ & $7(11.7 \%)$ & $17(25.4 \%)$ & \\
\hline Relationship to patient & & & & & & 0.007 \\
\hline Spouse & $136(44.7 \%)$ & $35(60.3 \%)$ & $47(39.8 \%)$ & $34(56.7 \%)$ & $20(29.4 \%)$ & \\
\hline Child & $151(49.7 \%)$ & $21(36.2 \%)$ & $62(52.5 \%)$ & $24(40.0 \%)$ & $44(64.7 \%)$ & \\
\hline Friend and family & $17(5.6 \%)$ & $2(3.4 \%)$ & $9(7.6 \%)$ & $2(3.3 \%)$ & $4(5.9 \%)$ & \\
\hline Resides with patient & & & & & & 0.097 \\
\hline Note. ECOG: Eastern Coop & ative Oncolog & Group & & & & \\
\hline
\end{tabular}




\begin{tabular}{|c|c|c|c|c|c|c|}
\hline & All sample & $\begin{array}{l}\text { Patient low- } \\
\text { caregiver low } \\
\text { profile }\end{array}$ & $\begin{array}{l}\text { Patient low- } \\
\text { caregiver high } \\
\text { profile }\end{array}$ & $\begin{array}{l}\text { Patient high- } \\
\text { caregiver low } \\
\text { profile }\end{array}$ & $\begin{array}{l}\text { Patient high- } \\
\text { caregiver } \\
\text { high profile }\end{array}$ & $\begin{array}{l}P \\
\text { value }\end{array}$ \\
\hline Yes & $205(67.4 \%)$ & $44(75.9 \%)$ & $71(60.2 \%)$ & $45(75.0 \%)$ & $45(66.2 \%)$ & \\
\hline No & $99(32.6 \%)$ & $14(24.1 \%)$ & $47(39.8 \%)$ & $15(25.0 \%)$ & $23(33.8 \%)$ & \\
\hline $\begin{array}{l}\text { Caregiving hours per } \\
\text { day }^{a}\end{array}$ & & & & & & 0.398 \\
\hline$\leq 8 \mathrm{~h}$ & $81(26.6 \%)$ & $15(25.9 \%)$ & $36(30.8 \%)$ & $10(16.9 \%)$ & $20(29.9 \%)$ & \\
\hline $9-16 h$ & $82(27.0 \%)$ & $17(29.3 \%)$ & $26(22.2 \%)$ & $18(30.5 \%)$ & $21(31.3 \%)$ & \\
\hline $17-24 \mathrm{~h}$ & $138(45.4 \%)$ & $26(44.8 \%)$ & $55(47.0 \%)$ & $31(52.5 \%)$ & $26(38.8 \%)$ & \\
\hline $\begin{array}{l}\text { Duration of caregiving } \\
\text { (month) }^{\mathrm{a}}\end{array}$ & $8.10 \pm 12.09$ & $9.38 \pm 15.50$ & $7.92 \pm 12.07$ & $7.50 \pm 7.92$ & $7.82 \pm 11.98$ & 0.837 \\
\hline Neuroticism & $22.19 \pm 5.85$ & $24.28 \pm 5.45$ & $21.92 \pm 5.94$ & $22.97 \pm 5.85$ & $20.18 \pm 5.39$ & 0.001 \\
\hline Resilience & $27.64 \pm 7.18$ & $24.79 \pm 8.46$ & $27.84 \pm 6.30$ & $26.15 \pm 7.41$ & $31.04 \pm 5.80$ & $<0.001$ \\
\hline Family functioning & $35.68 \pm 5.30$ & $35.02 \pm 5.20$ & $36.04 \pm 5.63$ & $34.34 \pm 4.73$ & $36.80 \pm 5.02$ & 0.039 \\
\hline \multicolumn{7}{|c|}{ Note. ECOG: Eastern Cooperative Oncology Group } \\
\hline
\end{tabular}

Table 2 Fit statistics: Patient-caregiver dyadic QoL latent profile analysis models

\begin{tabular}{|lllllllll|}
\hline Model & $\mathrm{K}$ & $\mathrm{AIC}$ & $\mathrm{BIC}$ & $\mathrm{aBIC}$ & Entropy & $\mathrm{LMR}(P)$ & $\mathrm{BLRT}(P)$ & Probability of classes \\
\hline $\begin{array}{l}1- \\
\text { class }\end{array}$ & 32 & 45456.808 & 45575.753 & 45474.265 & & & & 1.00 \\
\hline $\begin{array}{l}\text { 2- } \\
\text { class }\end{array}$ & 49 & 44579.384 & 44761.518 & 44606.115 & 0.870 & 0.007 & $<0.001$ & $0.54 / 0.46$ \\
\hline $\begin{array}{l}\text { 3- } \\
\text { class }\end{array}$ & 66 & 44088.927 & 44334.251 & 44124.932 & 0.891 & 0.233 & $<0.001$ & $0.40 / 0.30 / 0.30$ \\
\hline $\begin{array}{l}\mathbf{4 -} \\
\text { class }\end{array}$ & $\mathbf{8 3}$ & $\mathbf{4 3 7 8 4 . 0 0 1}$ & $\mathbf{4 4 0 9 2 . 5 1 4}$ & $\mathbf{4 3 8 2 9 . 2 8 0}$ & $\mathbf{0 . 9 1 5}$ & $\mathbf{0 . 0 1 9}$ & $<0.001$ & $\mathbf{0 . 3 9 / 0 . 2 2 / 0 . 2 0 / 0 . 1 9}$ \\
\hline $\begin{array}{l}\text { 5- } \\
\text { class }\end{array}$ & 100 & 43615.996 & 43987.699 & 43670.549 & 0.908 & 0.598 & $<0.001$ & $0.34 / 0.18 / 0.17 / 0.16 / 0.15$ \\
\hline $\begin{array}{l}\text { 6- } \\
\text { class }\end{array}$ & 117 & 43493.369 & 43928.262 & 43557.197 & 0.911 & 0.251 & $<0.001$ & $0.32 / 0.18 / 0.17 / 0.15 / 0.13 / 0.04$ \\
\hline $\begin{array}{l}7- \\
\text { class }\end{array}$ & 134 & 43427.699 & 43925.781 & 43500.800 & 0.899 & 0.770 & $<0.001$ & $0.20 / 0.17 / 0.17 / 0.16 / 0.13 / 0.13 / 0.04$ \\
\hline
\end{tabular}

Note. AIC: Akaike's information criterion; BIC: Bayesian information criterion; sBIC: sample-size-adjusted BIC; LMR: The Vuong-LoMendell-Rubin likelihood ratio test, BLRT bootstrapped likelihood ratio test.

Table 3 Potential predictors of latent profile membership 


\begin{tabular}{|c|c|c|c|c|c|c|c|c|c|}
\hline \multirow[t]{2}{*}{ characteristics } & \multicolumn{3}{|c|}{$\begin{array}{l}\text { Patient low-caregiver low } \\
\text { profile }\end{array}$} & \multicolumn{3}{|c|}{$\begin{array}{l}\text { Patient low-caregiver high } \\
\text { profile }\end{array}$} & \multicolumn{3}{|c|}{$\begin{array}{l}\text { Patient high- caregiver low } \\
\text { profile }\end{array}$} \\
\hline & OR & $95 \% \mathrm{Cl}$ & $P$ & OR & $95 \% \mathrm{Cl}$ & $P$ & OR & $95 \% \mathrm{Cl}$ & $P$ \\
\hline \multicolumn{10}{|l|}{ Patients } \\
\hline \multicolumn{10}{|l|}{ Economic situation } \\
\hline $\begin{array}{l}\text { Income lesser than the } \\
\text { expenditure }\end{array}$ & 5.749 & $\begin{array}{l}0.589- \\
56.127\end{array}$ & 0.132 & 5.943 & $\begin{array}{l}1.663- \\
21.240\end{array}$ & 0.006 & 0.653 & $\begin{array}{l}0.193- \\
2.213\end{array}$ & 0.494 \\
\hline $\begin{array}{l}\text { Income equal to the } \\
\text { expenditure }\end{array}$ & 5.251 & $\begin{array}{l}0.494- \\
55.791\end{array}$ & 0.169 & 1.764 & $\begin{array}{l}0.453- \\
6.871\end{array}$ & 0.413 & 0.263 & $\begin{array}{l}0.064- \\
1.083\end{array}$ & 0.064 \\
\hline $\begin{array}{l}\text { Income more than the } \\
\text { expenditure }\end{array}$ & Ref & & & Ref & & & Ref & & \\
\hline ECOG performance status & 3.058 & $\begin{array}{l}1.857- \\
5.037\end{array}$ & $<0.001$ & 2.350 & $\begin{array}{l}1.528- \\
3.615\end{array}$ & $<0.001$ & 1.572 & $\begin{array}{l}0.976- \\
2.531\end{array}$ & 0.063 \\
\hline Neuroticism & 1.125 & $\begin{array}{l}1.037- \\
1.221\end{array}$ & 0.005 & 1.072 & $\begin{array}{l}1.006- \\
1.142\end{array}$ & 0.032 & 1.074 & $\begin{array}{l}0.996- \\
1.158\end{array}$ & 0.064 \\
\hline Resilience & 1.006 & $\begin{array}{l}0.941- \\
1.075\end{array}$ & 0.866 & 0.970 & $\begin{array}{l}0.921- \\
1.022\end{array}$ & 0.252 & 1.037 & $\begin{array}{l}0.973- \\
1.105\end{array}$ & 0.264 \\
\hline Family functioning & 0.935 & $\begin{array}{l}0.853- \\
1.026\end{array}$ & 0.157 & 0.965 & $\begin{array}{l}0.895- \\
1.041\end{array}$ & 0.363 & 0.916 & $\begin{array}{l}0.841- \\
0.996\end{array}$ & 0.041 \\
\hline \multicolumn{10}{|l|}{ Caregivers } \\
\hline Age & 1.008 & $\begin{array}{l}0.955- \\
1.064\end{array}$ & 0.763 & 1.026 & $\begin{array}{l}0.982- \\
1.073\end{array}$ & 0.253 & 1.067 & $\begin{array}{l}1.013- \\
1.124\end{array}$ & 0.015 \\
\hline \multicolumn{10}{|l|}{ Economic situation } \\
\hline $\begin{array}{l}\text { Income lesser than the } \\
\text { expenditure }\end{array}$ & 2.150 & $\begin{array}{l}0.494- \\
9.352\end{array}$ & 0.307 & 0.919 & $\begin{array}{l}0.325- \\
2.598\end{array}$ & 0.873 & 2.231 & $\begin{array}{l}0.639- \\
7.795\end{array}$ & 0.209 \\
\hline $\begin{array}{l}\text { Income equal to the } \\
\text { expenditure }\end{array}$ & 1.609 & $\begin{array}{l}0.357- \\
7.237\end{array}$ & 0.536 & 0.995 & $\begin{array}{l}0.359- \\
2.763\end{array}$ & 0.993 & 2.078 & $\begin{array}{l}0.569- \\
7.592\end{array}$ & 0.268 \\
\hline $\begin{array}{l}\text { Income more than the } \\
\text { expenditure }\end{array}$ & Ref & & & Ref & & & Ref & & \\
\hline \multicolumn{10}{|l|}{ Relationship to patient } \\
\hline Spouse & 1.727 & $\begin{array}{l}0.191- \\
15.644\end{array}$ & 0.627 & 0.557 & $\begin{array}{l}0.106- \\
2.939\end{array}$ & 0.491 & 1.266 & $\begin{array}{l}0.165- \\
9.731\end{array}$ & 0.821 \\
\hline Child & 0.430 & $\begin{array}{l}0.050- \\
3.736\end{array}$ & 0.444 & 0.492 & $\begin{array}{l}0.100- \\
2.435\end{array}$ & 0.385 & 1.398 & $\begin{array}{l}0.192- \\
10.175\end{array}$ & 0.741 \\
\hline Friend and family & & & & Ref & & & & & \\
\hline Neuroticism & 1.073 & $\begin{array}{l}0.986- \\
1.169\end{array}$ & 0.103 & 1.037 & $\begin{array}{l}0.967- \\
1.113\end{array}$ & 0.311 & 1.068 & $\begin{array}{l}0.986- \\
1.156\end{array}$ & 0.108 \\
\hline Resilience & 0.897 & $\begin{array}{l}0.836- \\
0.962\end{array}$ & 0.002 & 0.956 & $\begin{array}{l}0.901- \\
1.013\end{array}$ & 0.128 & 0.922 & $\begin{array}{l}0.864- \\
0.983\end{array}$ & 0.014 \\
\hline Family functioning & 1.038 & $\begin{array}{l}0.934- \\
1.153\end{array}$ & 0.488 & 1.039 & $\begin{array}{l}0.953- \\
1.132\end{array}$ & 0.385 & 1.012 & $\begin{array}{l}0.919- \\
1.115\end{array}$ & 0.806 \\
\hline
\end{tabular}

Note. ECOG: Eastern Cooperative Oncology Group

Cl: confidence interval

The patient high-caregiver high profile was used as the reference group.

Table 4 The combined effect of patient-caregiver dyads' neuroticism, resilience, and family functioning on latent profile membership 


\begin{tabular}{|c|c|c|c|c|c|c|c|c|c|c|}
\hline \multicolumn{2}{|c|}{ Combined effect } & \multicolumn{3}{|c|}{$\begin{array}{l}\text { Patient low-caregiver high } \\
\text { profile }\end{array}$} & \multicolumn{3}{|c|}{$\begin{array}{l}\text { Patient high- caregiver low } \\
\text { profile }\end{array}$} & \multicolumn{3}{|c|}{$\begin{array}{l}\text { Patient low-caregiver low } \\
\text { profile }\end{array}$} \\
\hline $\begin{array}{l}\text { Patient } \\
\text { neuroticism }\end{array}$ & $\begin{array}{l}\text { Caregiver } \\
\text { neuroticism }\end{array}$ & OR & $95 \% \mathrm{Cl}$ & $P$ & OR & $95 \% \mathrm{Cl}$ & $P$ & OR & $95 \% \mathrm{Cl}$ & $P$ \\
\hline Low & Low & Reference & & & Reference & & & Reference & & \\
\hline High & Low & 3.210 & $\begin{array}{l}1.256- \\
8.200\end{array}$ & 0.015 & 2.032 & $\begin{array}{l}0.680- \\
6.070\end{array}$ & 0.204 & 9.167 & $\begin{array}{l}2.480- \\
33.886\end{array}$ & 0.001 \\
\hline Low & High & 1.365 & $\begin{array}{l}0.527- \\
3.535\end{array}$ & 0.522 & 2.066 & $\begin{array}{l}0.726- \\
5.876\end{array}$ & 0.174 & 4.247 & $\begin{array}{l}1.125- \\
16.027\end{array}$ & 0.033 \\
\hline High & High & 2.520 & $\begin{array}{l}0.974- \\
6.520\end{array}$ & 0.057 & 3.920 & $\begin{array}{l}1.353- \\
11.359\end{array}$ & 0.012 & 10.869 & $\begin{array}{l}3.041- \\
38.849\end{array}$ & $<0.001$ \\
\hline $\begin{array}{l}\text { Patient } \\
\text { resilience }\end{array}$ & $\begin{array}{l}\text { Caregiver } \\
\text { resilience }\end{array}$ & OR & $95 \% \mathrm{Cl}$ & $\mathrm{P}$ & OR & $95 \% \mathrm{Cl}$ & $P$ & OR & $95 \% \mathrm{Cl}$ & $P$ \\
\hline High & High & Reference & & & Reference & & & Reference & & \\
\hline Low & High & 2.727 & $\begin{array}{l}1.101- \\
6.758\end{array}$ & 0.030 & 1.721 & $\begin{array}{l}0.566- \\
5.230\end{array}$ & 0.338 & 2.223 & $\begin{array}{l}0.705- \\
7.051\end{array}$ & 0.173 \\
\hline High & Low & 1.367 & $\begin{array}{l}0.487- \\
3.838\end{array}$ & 0.553 & 4.088 & $\begin{array}{l}1.428- \\
11.702\end{array}$ & 0.009 & 4.331 & $\begin{array}{l}1.367- \\
13.726\end{array}$ & 0.013 \\
\hline Low & Low & 7.271 & $\begin{array}{l}2.412- \\
21.925\end{array}$ & $<0.001$ & 8.620 & $\begin{array}{l}2.555- \\
29.078\end{array}$ & 0.001 & 11.340 & $\begin{array}{l}3.221- \\
39.921\end{array}$ & $<0.001$ \\
\hline $\begin{array}{l}\text { Patient } \\
\text { family } \\
\text { functioning }\end{array}$ & $\begin{array}{l}\text { Caregiver } \\
\text { family } \\
\text { functioning }\end{array}$ & OR & $95 \% \mathrm{Cl}$ & $P$ & OR & $95 \% \mathrm{Cl}$ & $P$ & OR & $95 \% \mathrm{Cl}$ & $P$ \\
\hline High & High & Reference & & & Reference & & & Reference & & \\
\hline Low & High & 1.236 & $\begin{array}{l}0.511- \\
2.987\end{array}$ & 0.638 & 1.011 & $\begin{array}{l}0.338- \\
3.027\end{array}$ & 0.984 & 0.498 & $\begin{array}{l}0.148- \\
1.677\end{array}$ & 0.260 \\
\hline High & Low & 0.502 & $\begin{array}{l}0.176- \\
1.434\end{array}$ & 0.198 & 1.044 & $\begin{array}{l}0.316- \\
3.453\end{array}$ & 0.994 & 1.286 & $\begin{array}{l}0.407- \\
4.062\end{array}$ & 0.668 \\
\hline Low & Low & 1.916 & $\begin{array}{l}0.756- \\
4.853\end{array}$ & 0.170 & 5.453 & $\begin{array}{l}1.914- \\
15.537\end{array}$ & 0.001 & 2.944 & $\begin{array}{l}1.039- \\
8.344\end{array}$ & 0.042 \\
\hline
\end{tabular}

Note. Cl: confidence interval

The patient high-caregiver high profile was used as the reference group.

Model adjusted for significant demographic variables (patient's economic situation, ECOG performance status; caregiver's age, economic situation, relationship to patient). 


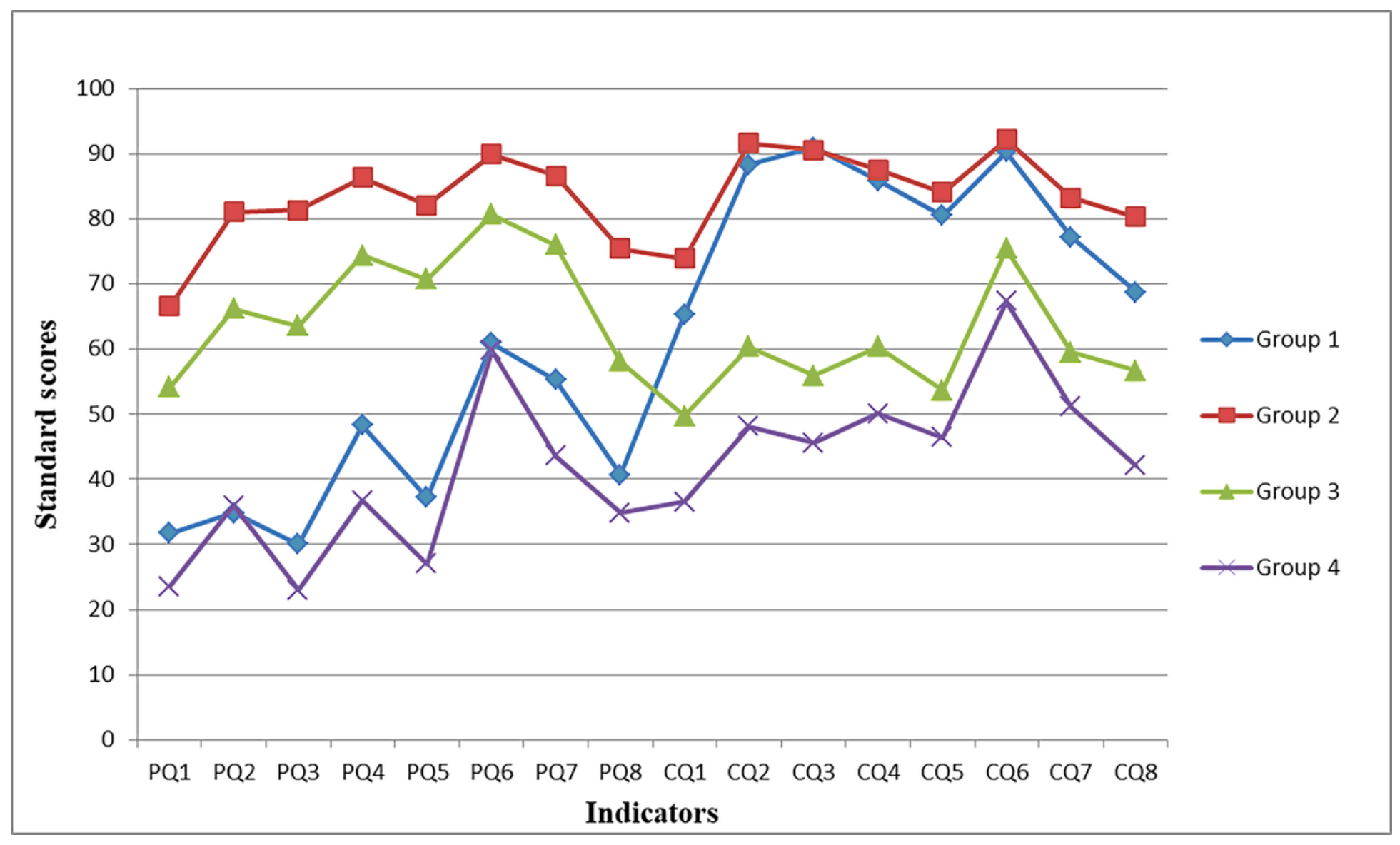

Figure 1

Dyadic quality of life profiles in advanced lung cancer patient-caregiver dyads

PQ1 represents general health perceptions (patients), PQ2 represents physical functioning (patients), PQ3 represents physical role (patients), PQ4 represents social functioning (patients), PQ5 represents emotional role (patients), PQ6 represents bodily pain (patients), PQ7 represents mental health (patients), PQ8 represents vitality (patients); CQ1 represents general health perceptions (caregivers), CQ2 represents physical functioning (caregivers), CQ3 represents physical role (caregivers), CQ4 represents social functioning (caregivers), CQ5 represents emotional role (caregivers), CQ6 represents bodily pain (caregivers) , CQ7 represents mental health (caregivers), CQ8 represents vitality (caregivers).

Group 1: Patient low-caregiver high profile; Group 2: Patient high-caregiver high profile; Group 3: Patient high-caregiver low profile; Group 4: Patient low-caregiver low profile 